\title{
Application Research of Asphalt concrete composite structure in the bridge deck pavement
}

\author{
Wei Hui ${ }^{12, a}$ Li Wei ${ }^{34, b}$ \\ ${ }^{1}$ Key Laboratory of Road Structure and Material of Guangxi, Nanning, 530007, China \\ ${ }^{2}$ School of Transportation Engineering, Changsha University of Science and Technology, \\ Changsha, 410076, China \\ ${ }^{3}$ Henan Transportation Research Institute CO.,LTD ,Zhengzhou 450006, China \\ ${ }^{4}$ State Engineering Laboratory of Highway Maintenance Technology, Changsha University of \\ Science \& Technology , Changsha, 410076, China \\ a65234551@qq.com, b liwei11254@126.com
}

Keywords: Road engineering; Bridge deck pavement; Asphalt concrete; Composite structure; Structure performance

\begin{abstract}
Asphalt concrete composite structure has important influence on the performance of bridge deck pavement road. In order to optimize the design the surfacing layer composite structure, using the thick type rut test, direct shear test and low temperature bending test to verifies the performance of asphalt concrete; Empirical research indicates that the dual SMA composite structures has significant advantages in the high temperature stability, shearing and anti-crack performance; Above and below layer structure type has a decisive role to the high temperature anti-rutting and the low temperature crack resistance, respectively. Rubber powder modified asphalt improves the layer structure of high temperature and low temperature performance, but it can't improve the shear resistance. Summarize research results, Bridge overlay is a special pavement structure, which recommended according to maximum grain with small top and big bottom double SMA structure combinations, to solve the current bridge deck pavement premature problem such as rutting, goes on to provide technical support.
\end{abstract}

\section{Introduction}

The bridge deck pavement, as an important part of the bridge, has a direct impact on driving safety, comfort and durability of the bridge. Asphalt concrete pavement structure can not only ease traffic load on the impact of the bridge deck and improve the durability of concrete Bridges, but also can improve the deck flatness, that to increase the comfort of driving. But the research on bridge deck pavement starts late in our country, and research areas are mainly concentrated in long-span steel bridge deck pavement technology, research on cement concrete bridge deck pavement system is less. In recent years, a majority of cement concrete bridge deck asphalt concrete pavement appeared bond layer shear failure, rutting, passes, package and fatigue damage phenomenon.

The type of bridge deck pavement structure and material performance directly determines the quality of bridge deck pavement. Many scholars both at home and abroad are working to improve asphalt concrete bridge deck pavement structure type resistance to fatigue, shear and high temperature performance of research, and has obtained the certain research progress, such as the 
SMA, rubber asphalt mixture in the middle of the bridge deck pavement structure widely adopted, its improve the performance of the bridge deck pavement structure, to a certain extent. When vehicle loads on bridge deck pavement layer produced by shear stress more than compressive strength, Surfacing can appear wave ups and downs or bond layer shear failure; when the shear stress exceeds structure of shear strength, asphalt concrete will appear rut. Therefore, its from the combination of pavement structure performance, through the use of asphalt concrete layer and composite layer performance combination method, which studies the different types of various properties of the surfacing layer, and to optimize the bridge deck pavement typical structure.

\section{Materials and methods}

This paper Puts forward several kinds of pavement structure combination(table 4), by studying literature research and combined with the pavement's functional requirements.

(1) Combination I,double SMA structure as the main research object. This structure is often used in bridge deck pavement of long-span. Drew up the top layer of the SBS modified asphalt SMA-13, below layer for SBS modified asphalt SMA-16 structure combinations.

(2) Combination II,top layer of SBS modified asphalt SMA-13, that to ensure the shear resistance and temperature stability of the bridge, the following layer for SBS modified asphalt AC-10, which used in water proof, resistance to deformation.

(3) combination III,top layer of rubber powder modified asphalt by SBS composite SMA-13,for the SBS modified asphalt AC-10 below layer.

(4) combination IV, double AC structure, forms commonly used for bridge deck pavement structure. The above layer for SBS modified asphalt AC-13, for the SBS modified asphalt AC-20 below layer.

Table 1 Pavement structure combination

\begin{tabular}{|c|c|c|c|c|}
\hline Typle & Structure & \multicolumn{3}{|c|}{ Asphalt mixture type } \\
\hline \multirow{2}{*}{ I } & Above & SBS SMA-13 & SBS SMA-16 & SBS SMA-13 \\
\cline { 2 - 5 } & Below & SBS SMA-16 & SBS SMA-13 & SBS SMA-10 \\
\hline \multirow{2}{*}{ II } & Above & \multicolumn{3}{|c|}{ SBS SMA-13 } \\
\cline { 2 - 5 } & Below & SBS AC-10 \\
\hline \multirow{2}{*}{ III } & Above & Rubber powder modified asphalt+SBS SMA-13 \\
\cline { 2 - 5 } & Below & SBS AC-10 \\
\hline \multirow{2}{*}{ IV } & Above & SBS AC-13 \\
\cline { 2 - 5 } & Below & SBS AC-20 \\
\hline
\end{tabular}

\section{High temperature performance}

Verify the high temperature performance of asphalt pavement method is relatively mature, including bending creep test, rutting test, large ring road and the scene accelerated loading rutting test, etc. In this paper, we choose conventional rut test, proposed by routine and composite compact combination method, verify the high temperature stability of the concrete bridge deck pavement layer. The experiment scheme is simple operation, and can better reflect the high temperature of pavement rutting resistance.

The surfacing layer of the specimen size is $30 \mathrm{~cm} * 30 \mathrm{~cm} * 10 \mathrm{~cm}$, consists of two layers, upper and lower two layer thickness is $4 \mathrm{~cm}$ and $6 \mathrm{~cm}$ respectively. Experiments in rut mold making first $6 \mathrm{~cm}$ below the layer, place 1 days after ripping, put it in the total thickness type plate, after 
besmear to brush the SBS modified asphalt sticky layer of oil, to suppress the layer above. Rutting test specimens after the wheel track and cut surface of the specimens, as shown in figure 2.

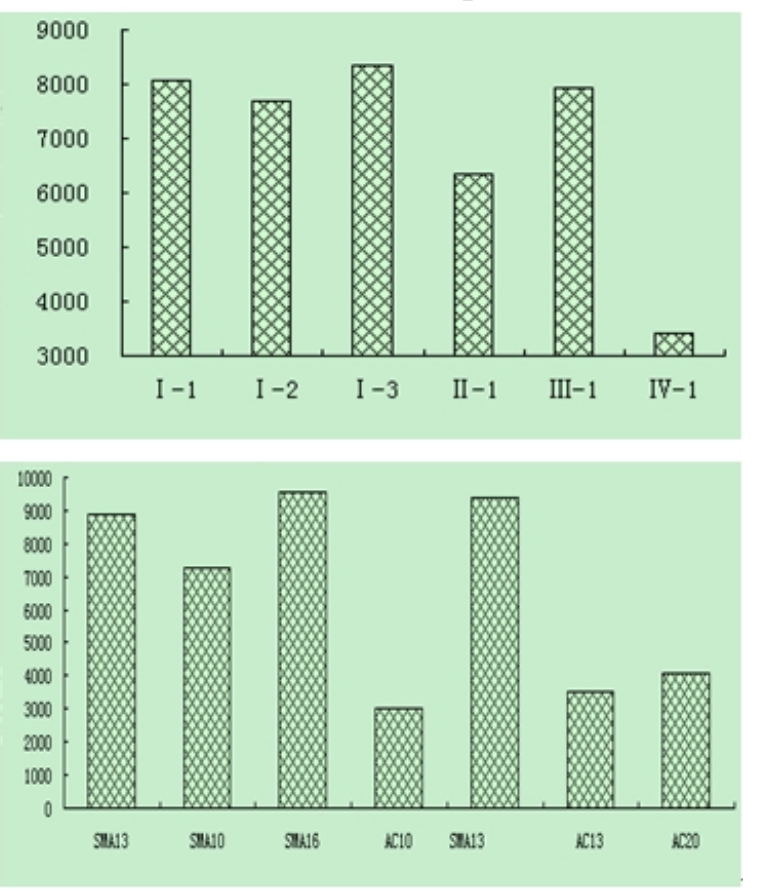

Figure 2 Structure type impact on dynamic stability Figure 3 Mixture gradation type impact on dynamic stability

From these data: (1) there is a close relationship between the structure combination and higher-temperature deformation resistance of the bridge. Overall, the skeleton embedded structure has good high temperature performance, especially for the special of the deck surfacing structures. In this paper, we put forward with double structure combination form of SMA, it has more obvious advantages than other structure.

(2) Contrast IIand III structure of the test results, the same structure combination adding rubber powder modified the structure of the dynamic stability is bigger, the dynamic stability is increased by $25 \%$ without adding the structure, it has better anti-rutting ability. The addition of rubber powder can largely improve the high temperature stability of the surfacing layer. Most of the structural combination of the dynamic stability depends on the layer above.

(3) IV is conventional surfacing layer form, test results show that the type of composite structure as a whole dynamic stability is bad; Due to the low layer below AC10 dynamic stability and single layer above the SBS modified asphalt, so the dynamic stability is low. In addition, other structural combination of dynamic stability compared with its corresponding layer above the structure dynamic stability by $5 \% \sim 15 \%$.

\section{Low temperature performance}

Low-temperature cracking is one of main disease. The early cracking of pavement not only affect the road appearance and drive comfort, and the most important thing is that greatly shortens the service life of road surface. that study used a low temperature bending test to evaluation of asphalt mixture performance at low temperature, according to the midcap deflection of beam body with flexural stress, strain and stiffness modulus, Composite trabecular low-temperature bending test results are shown in table 2 . 
Table 2 Composite beam bending test at low temperature

\begin{tabular}{|c|c|c|c|c|}
\hline Type & $\begin{array}{c}\text { fracture load } \\
(\mathrm{KN})\end{array}$ & $\begin{array}{c}\text { bending tensile strength } \\
\mathrm{R}_{\mathrm{B}}(\mathrm{MPa})\end{array}$ & $\begin{array}{c}\text { mid-span } \\
\text { deflection } \mathrm{u} \\
(\mathrm{mm})\end{array}$ & $\begin{array}{c}\text { maximum } \\
\text { bending strain } \\
\varepsilon_{\mathrm{B}}\end{array}$ \\
\hline $\mathrm{I}-1$ & 4.0 & 9.7 & 0.9 & 0.00667 \\
\hline $\mathrm{I}-2$ & 4.5 & 10.8 & 1.0 & 0.00740 \\
\hline $\mathrm{I}-3$ & 3.7 & 8.9 & 0.8 & 0.00615 \\
\hline II-1 & 3.7 & 9.0 & 0.8 & 0.00623 \\
\hline III-1 & 4.0 & 9.4 & 0.9 & 0.00662 \\
\hline IV-1 & 2.8 & 6.7 & 0.8 & 0.00563 \\
\hline
\end{tabular}

(1) On the whole analysis, SMA composite structure not only has significant advantages in the high temperature stability performance and shear performance, also has good performance in low temperature crack resistance. Worst crack resistance of the double AC structure combination, shows that the structure of AC composite applications in the surfacing layer corresponding defects, which for easy to appear problem under special conditions.

(2) By comparing the II, III structures, rubber powder improved the structure layer failure strain, it shows that rubber powder can improve the structure of the layer of the low temperature crack resistance to a certain extent.

(3) Double SMA structure size smallerI-2 inversion structure has the most low temperature crack resistance. SMA-10 as layer structure under the low temperature crack resistance than AC-10 will increase by $19 \%$. Thus the structure type determines the pavement layer's overall low temperature crack resistance, in the study of the surfacing layer, improve pavement's crack resistance at low temperature can be start from the structure type of layer below.

\section{Conclusion}

(1) Double SMA structure has significant high temperature rutting resistance, shear resistance and low temperature crack resistance, the performance of the dual structure of AC is poorer, it is one of the most important reasons important reasons for bridge deck pavement rutting. Research indicates that the recommended SMA composite structure to meet the road performance in case of special requirements.

(2) For the same type of mixture structure, nominal maximum aggregate size has a significant impact on performance, the top layer structure have a significant influence to rut, and the following structure type decide the whole low temperature crack resistance. In order to cold area temperature and low temperature crack resistance requirements of the surfacing layer. Which recommended according to the structure of the nominal maximum particle size on the small combinations.

(3) Through the stress analysis, large span bridge hill road pavement should have good anti-rutting performance and downhill road pavement requirements of shear performance of pavement. Rubber powder can improve the comprehensive performance of asphalt cement, to improve the pavement anti-rutting performance at high temperatures and low temperature crack resistance, but there is no significant influence on the shear capacity .

\section{Reference}

[1] Shen jinan, Zhang chengliang. Bitumen and Bituminous Mixtures pavement performance [M]. 
Beijin:China communication press, 2001.

[2] JTGE20-2011, Bitumen and Bituminous Mixtures for Highway Engineering[S]. Beijin:China communication press, 2011.

[3] Huang Wei Liu Zhen-qing. Research on theory and method of long-span steel bridges deck surfacing design [J]. China Civil Engineering Journal, 2004.

[4] The ministry of communications highway science institute. Quality inspection and evaluation standards for highway engineering (JTG F80/2-2004) [S]. Beijin: China communication press, 2004.

[5] Chen yanjun. Experimental study of asphalt overlay on the deck of long-span concrete bridge [D]. Chang 'an university, master's degree thesis, 2010.

[6] Zhang lingxian. Cement concrete bridge deck surfacing layer structure rationality [D]. Chang 'an university, master's degree thesis, 2008.

[7] Cui jianwei. Bridge deck pavement structure performance numerical simulation analysis [D]. Zheng zhou university, master's degree thesis, 2005.

[8] Wang shaohua. The structure of the continuous girder bridge asphalt concrete deck pavement design research [D]. Shan dong university, master's degree thesis, 2008. 